\title{
Ares V: Progress Towards a Heavy Lift Capability for the Moon and Beyond
}

\author{
Steve Creech, Integration Manager, Ares V \\ Ares Projects Office \\ Marshall Space Flight Center \\ Huntsville, AL 35812
}

\begin{abstract}
NASA's new exploration initiative will again take humans beyond low Earth orbit, to the moon, and into deep space. The space agency is developing a new fleet of launch vehicles that will fulfill the national goals of replacing the Space Shuttle fleet, completing the International Space Station, establishing a permanent outpost on the moon, and eventually traveling to Mars. Separate crew and cargo vehicles emerged from mission architecture studies - the Ares I to carry the Orion crew exploration vehicle and its crew of 4 to 6 astronauts, and the Ares V to carry the Altair lunar lander or other supplies to support future exploration missions. (Figure 1) These vehicles will be designed to be safe, affordable, sustainable, reliable, operable with the safety, reliability, flexibility, and operability to serve this nation's manned and unmanned exploration programs for the coming decades. This paper discusses recent and current progress on the Ares V and planned future activities.
\end{abstract}

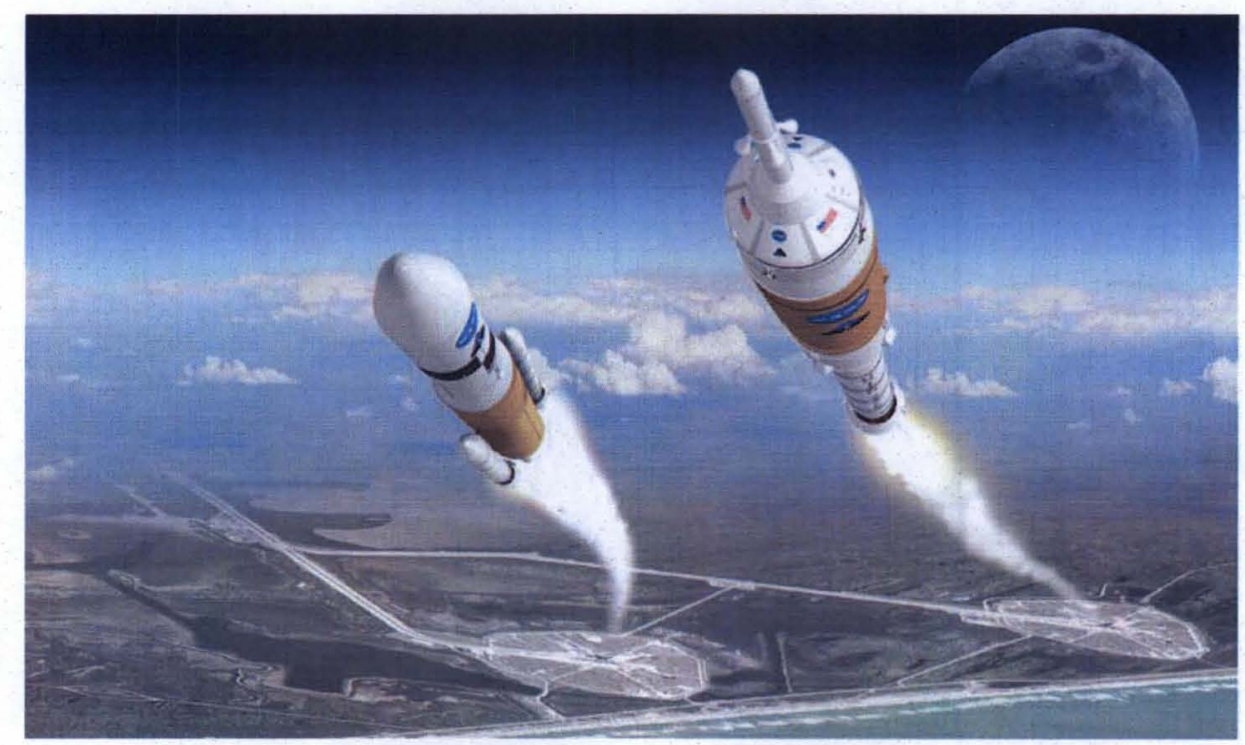

Figure 1. The Ares V Cargo Launch Vehicle (left) and Ares I Crew Launch Vehicle (right) will form the backbone of America's new space fleet. (NASA artist's concept)

In its present configuration, Ares $V$ stands 360 feet $(109.7 \mathrm{~m})$ tall, with a gross liftoff mass of 7.4 million pounds $(3.3 \mathrm{~kg})$. It will lift 138,000 pounds $(62,596 \mathrm{~kg})$ to trans lunar injection (TLI) in dual launch mode with Ares I or 287,000 pounds $(130,000 \mathrm{~kg}$ ) to low earth orbit (LEO) in single launch mode. 
By comparison, The Apollo-era Saturn V was 364 feet $(110.9 \mathrm{~m})$ tall, with a gross liftoff mass of 6.5 million pounds $(2,948,350 \mathrm{~kg})$, and could carry 99,000 pounds $(44,906 \mathrm{~kg})$ to TLI or 262,000 pounds $(118,841 \mathrm{~kg})$ to LEO.

The Ares Projects Office (APO) in 2006 and early 2007 used "seed money" from Congress to perform early engineering analyses on mission, trajectory and design of the Core Stage. Core Stage work focused on the engine, originally determined to be a low-cost variant of the Space Shuttle Main Engine but later changed to be an evolved variant of the commercially-available RS-68. Since that effort concluded, a variety of programmatic and technical activities have been conducted at NASA's Marshall Space Flight Center, as well as other NASA centers around the country.

APO and supporting organizations are assessing further performance enhancement options, including cost and reliability factors. The current baseline vehicle employs a Solid Rocket Booster design with a steel case and PBAN propellant. The baseline also provides for selected use of composites in Earth Departure Stage (EDS) structures. Ongoing analyses are considering the benefits, costs, and challenges of: more energetic HTPB propellant, a lighter composite booster case, an inert spacer that would permit enlarged Core Stage tankage, addition of a sixth RS-68 engine to the Core Stage, composite Core Stage dry structures, and composite EDS structures and tankage. Current ground rules and assumptions for these studies include: a four-day loiter, 29-degree, 130-nautical-mile insertion, 120-nautical-mile TLI departure, and 75.1-ton TLI payload requirement.

Several changes have occurred in the reference configurations. Total stack length decreased from 361.9 feet to 359.7 feet. Loiter decreased from 14 days to 4 days. LEO delivery orbit increased from 120 nautical miles at 28.5 degrees to 130 nautical miles at 29 degrees. TLI payload from 100 nautical miles increased from 60.6 metric tons to 62.8 metric tons. LEO FPR increased from 5,319 pounds to 7.692 pounds. The payload envelope increased from $33 \times 24.5$ feet to $25.3 \times 33$ feet. Shroud jettison mass increased from 12,868 pounds to 19,388 pounds.

EDS analysis suggests that the 8.4-meter stage, including Altair and Orion, exhibits a natural preference for gravity gradient orientation for minimum propellant consumption. The designs for Orion and Altair, notably power, thermal, and communications, prefer or require non-gravity gradient positioning that would impose a 9,000-pound propellant demand on the EDS during loiter. Possible solutions to avoid the propellant penalty include adding thermal, power and communications accommodations on the EDS. In the meantime, analysis of a 10-meter EDS option and requirements is ongoing.

Ares V planning benefits from the decision to seek commonality between Ares I and Ares V and tap existing propulsion technology where feasible. Work continues on the 5-segment Solid Rocket Booster for Ares I that will also be used in tandem for the Ares V. The APO is also moving ahead with enhancements to the Pratt \& Whitney Rocketdyne RS-68 engine that will power the Ares V Core Stage. (Figure 2) Helium spin start testing on the engine at Stennis Space Center is planned for later this year. Forgings for the required modifications purchased with 2007 funding are due to be delivered to MSFC in 2008. This potential intermediate seal redesign could reduce consumption of increasingly expensive helium. Pratt \& Whitney Rocketdyne proposes to design and build a development gas generator and helium spin start duct based on the seal test results and also to bring the design of a segmented carbon ring seal to critical design review level, allowing for testing at MSFC. These efforts can be completed before authority to proceed (ATP) in 2011 and will save a year in schedule and allow for Main Propulsion Test Article (MPTA) engines to be delivered on time. 


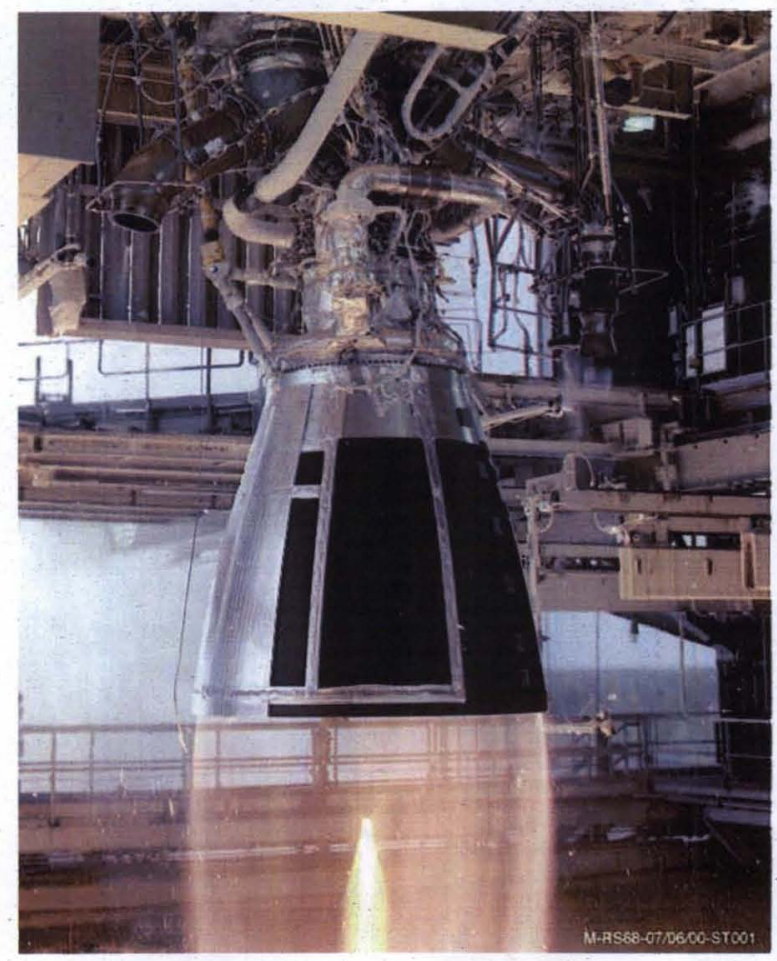

Figure 2. RS-68 during testing.

Numerous other activities are under way to better position Ares V for its anticipated 2011 Authority to Proceed date.

Based on a risk technical interchange meeting, Air Force RS-68 work, and technology value stream activities, the Ares Projects Office has generated a list of risk items to be monitored. Meetings to discuss Ares V utilization were conduced with Science and Mission Systems Directorate at Marshall Space Flight Center and National Reconnaissance Office. Engineers also conducted a technical interchange meeting to discuss facilities requirements for Ares V testing.

APO continues to: support the Constellation Program Lunar Capability Concept Review (LCCR) and lunar lander interface activities, assess test facilities requirements across all test sites, define the acquisition approach and pre-ATP industry/academia involvement, and plan new design analysis cycle (DAC) activities to support LCCR milestones. Glenn Research Center is leading a study of the Earth Departure Stage with updates for a payload shroud with a 10-meter outer mold line and a four-day loiter period. Follow-on Core Stage engineering and manufacturing risk mitigation studies are also planned for 2008 .

Studies also conclude that the Ares $\mathrm{V}$ lift requirement needs better understanding and definition. The Constellation Architecture Requirements Document baselines a 45-metric-ton lunar lander subject to growth. The performance requirement is also subject to growth resulting from mandated performance reserves, ASE/payload adapter provisions, and a desire for increased lander surface payloads.

Technologies that require better understanding and development include long-term cryogenic storage, EDS state determination, manufacturing, damage tolerance and detection, and joining of composite 
materials, on-orbit fluid management, tank insulation techniques, HTPB propellant characterization, and RS-68 performance enhancements.

These and other ongoing studies, analyses, and tests will ensure that Ares V can meet its scheduled test flight program late in the next decade and support human flights to the moon in the 2020 timeframe. 


\title{
Ares V: Progress Toward a Heavy Lift Capability for the Moon and Beyond
}

\author{
Steve Creech ${ }^{1}$ and Phil Sumrall ${ }^{2}$ \\ NASA Marshall Space Flight Center \\ Huntsville, Alabama 35812
}

NASA's new exploration initiative will again take humans beyond low Earth orbit to the moon and destinations beyond. The agency is developing a new fleet of launch vehicles that will fulfill the national goals of replacing the Space Shuttle fleet, completing the International Space Station, establishing a permanent outpost on the moon, and eventually traveling to Mars. Separate crew and cargo vehicles emerged from mission architecture studies - the Ares I to carry the Orion crew exploration vehicle and its crew of 4 to 6 astronauts, and the Ares V to carry the Altair lunar lander or other supplies to support future exploration missions (Figure 1). These vehicles will be designed to be safe, affordable, sustainable, reliable, and operable to serve this nation's manned and unmanned exploration programs for the coming decades. This paper discusses progress on the Ares $\mathrm{V}$, its evolutionary path to its present configuration, and planned future activities.

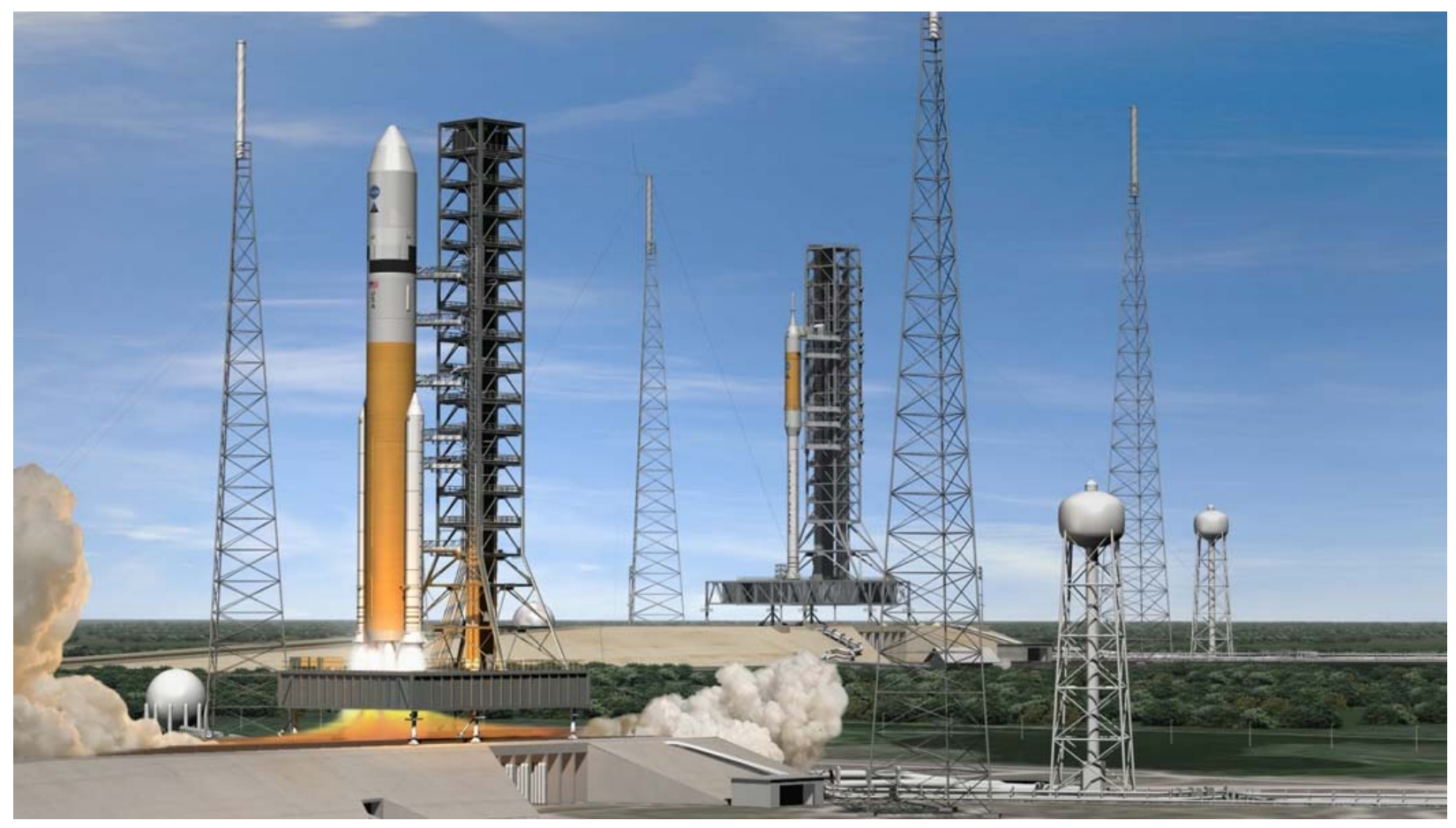

Figure 1. The Ares V cargo launch vehicle (left) and Ares I crew launch vehicle (right) will form the backbone of America's new space fleet. (NASA artist's concept)

\section{Introduction}

The Ares Projects at NASA's Marshall Space Flight Center (MSFC) are developing the Ares I crew launch vehicle and the Ares V cargo launch vehicle as a part of U.S. Space Exploration Policy and NASA's Global

\footnotetext{
${ }^{1}$ Ares V Integration Manager, Ares Projects

${ }^{2}$ Advanced Planning Manager, Ares Projects
} 
Exploration Strategy. These vehicles are the result of initial architecture studies focused on safe, reliable, operationally efficient vehicles that could support sustained long-term exploration. That architecture consisted of two vehicles, separating a smaller, simpler crew launch vehicle from the larger, more complex cargo launch vehicle as recommended by the post-Columbia accident investigation. Together, these vehicles represent a safer, more efficient, affordable, and robust launch solution than a single vehicle for missions as diverse as space station resupply in low Earth orbit (LEO) or large expeditions to the Moon or Mars. For both fiscal and reliability reasons, they are derived from technologies proven in the Saturn, Space Shuttle, and contemporary launch vehicle programs. They also employ to the extent feasible common components.

Ares I will be operational first, ferrying the Orion crew exploration vehicle to the ISS no later than 2015. Orion will be able to carry up to six astronauts to the station or support up to four astronauts for expeditions to the Moon. Ares $\mathrm{V}$ is scheduled to be available in the 2020 timeframe. Its primary mission will be to place the Altair lunar lander into Earth orbit and then send the lander and Orion, launched separately on Ares I, into a trans-lunar cruise trajectory. It will continue to serve as a cargo vehicle for human and cargo landers, rovers, habitats, power systems, and other supplies needed to vastly expand lunar exploration from the narrow equatorial band of the Apollo missions to virtually anywhere on the lunar surface.

In its latest configuration (Figure 2), approved in the recent Lunar Capabilities Concept Review (LCCR), the Ares V stands 381 feet (116 meters (m)) tall, with a gross liftoff mass of 8.1 million pounds (3,704 metric tons $(\mathrm{mT})$ ). It will lift a record 156,700 pounds $(71.1 \mathrm{mT})$ to trans lunar injection (TLI) in dual-launch mode with Ares I or 413,800 pounds $(187.7 \mathrm{mT})$ to low Earth orbit (LEO) in single-launch mode. By comparison, The Apollo-era Saturn V was 364 feet $(110.9 \mathrm{~m})$ tall, with a gross liftoff mass of 6.5 million pounds (2,948,350 kilograms $(\mathrm{kg}))$, and could carry 99,000 pounds $(44,906 \mathrm{~kg})$ to TLI or 262,000 pounds $(118,841 \mathrm{~kg})$ to LEO.

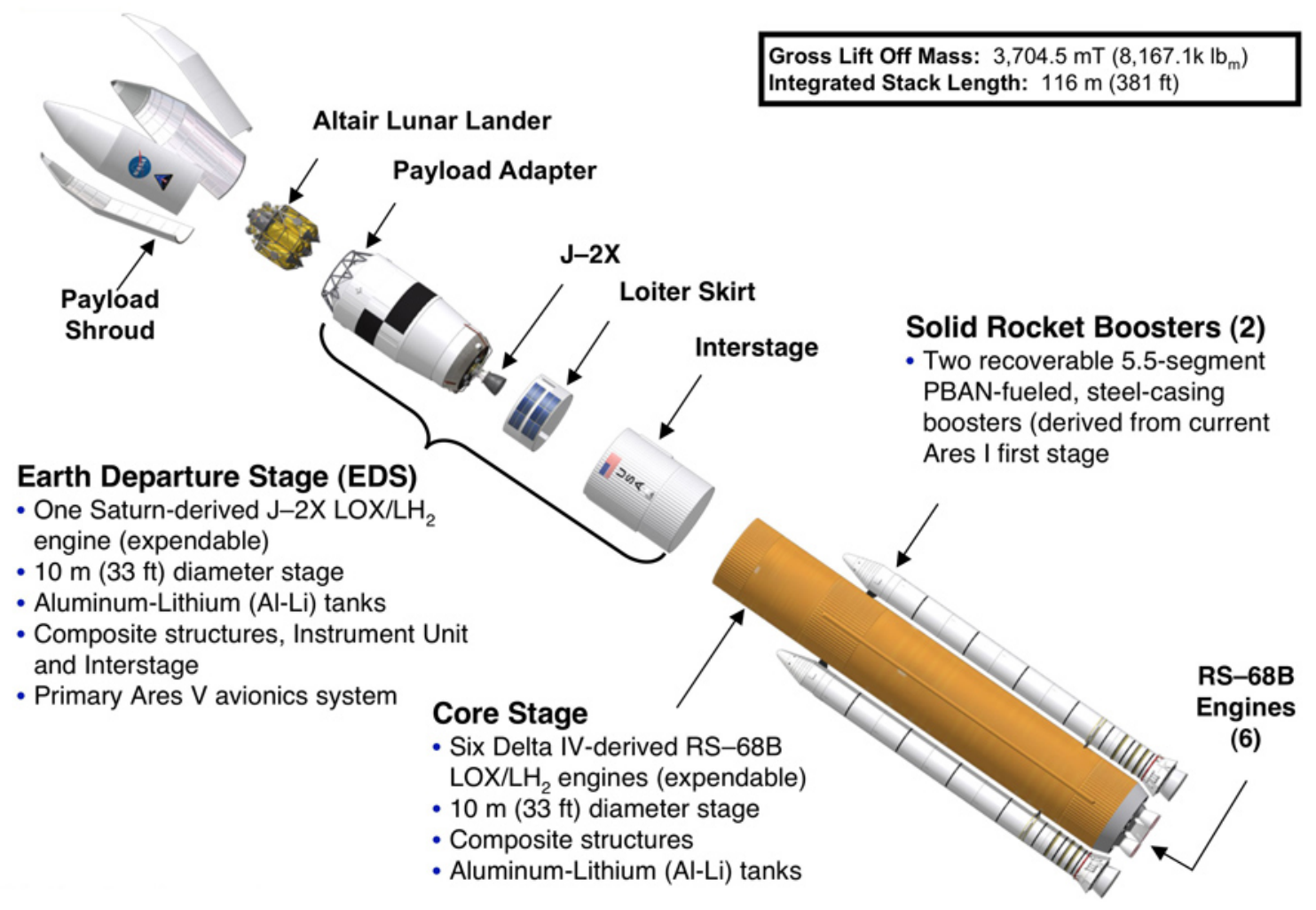

Figure 2. An expanded view of the major Ares V elements (NASA artist's concept)

Ares V's first stage propulsion consists of a core stage and two solid-propellant boosters. The core stage is powered by six commercial liquid hydrogen/liquid oxygen $\left(\mathrm{LH}_{2} / \mathrm{LOX}\right) \mathrm{RS}-68$ engines, adapted from the Delta IV program (Figure 3) to include additional operation time and reduce helium usage and free hydrogen at the base of the vehicle. 


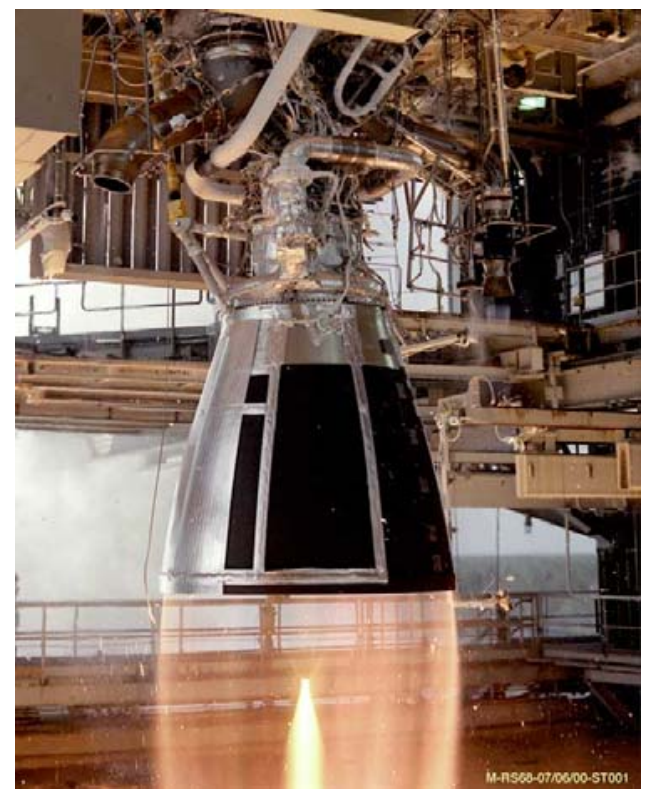

Figure 3. RS-68 during testing.

The 5.5-segment solid rocket boosters are similar to the Ares I 5-segment first stage now in development, which in turn is based on the current 4-segment Space Shuttle. Upper-stage propulsion consists of an Earth departure stage (EDS), powered by a single J-2X altitude-start engine, also now in development for Ares I. A payload adapter atop the EDS supports the Altair payload within the largest payload volume of any launch vehicle in history. Designed to carry the Altair lunar lander or other large payloads, the usable volume beneath the payload shroud, shown in Figure 4 , is nearly three times larger than the current Space Shuttle payload bay volume.
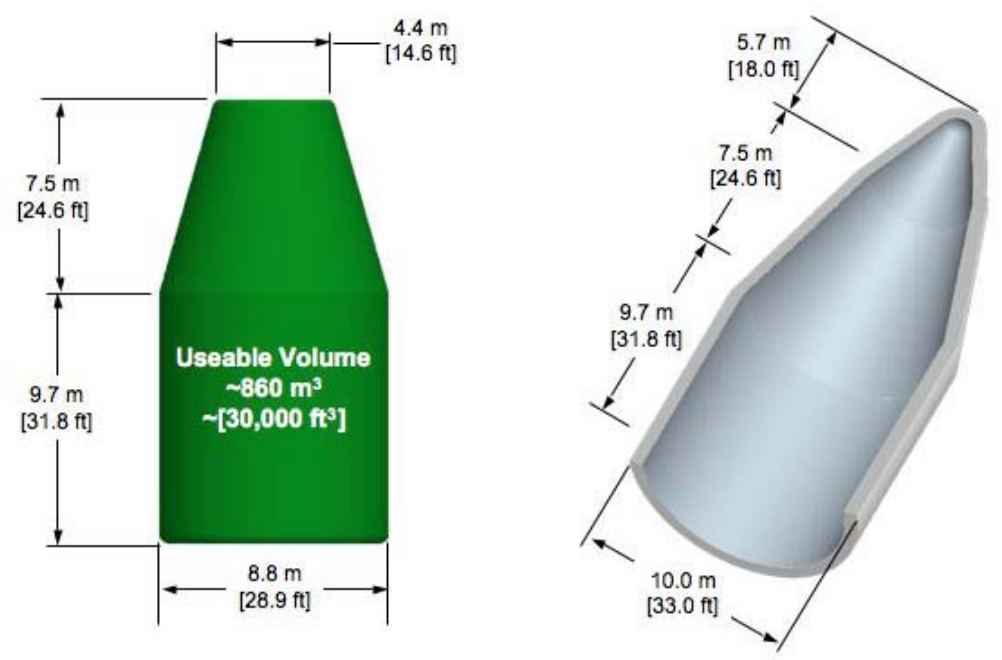

Figure 4: Ares V payload shroud outer dimensions and usable volume.

A nominal Ares V mission (Figure 5) would begin with a launch from Kennedy Space Center, FL. Following booster separation and core staging, the EDS would ignite at approximately 100,000 feet and place the EDS/payload into a stable parking orbit. Shroud separation would occur following EDS ignition. The Orion crew exploration vehicle, launched by the Ares I, would rendezvous and dock with the Altair. Following system checkouts, the EDS 
would reignite and perform a TLI burn to send the combined vehicles toward the Moon. The EDS would be discarded en route, completing the Ares portion of the lunar mission.

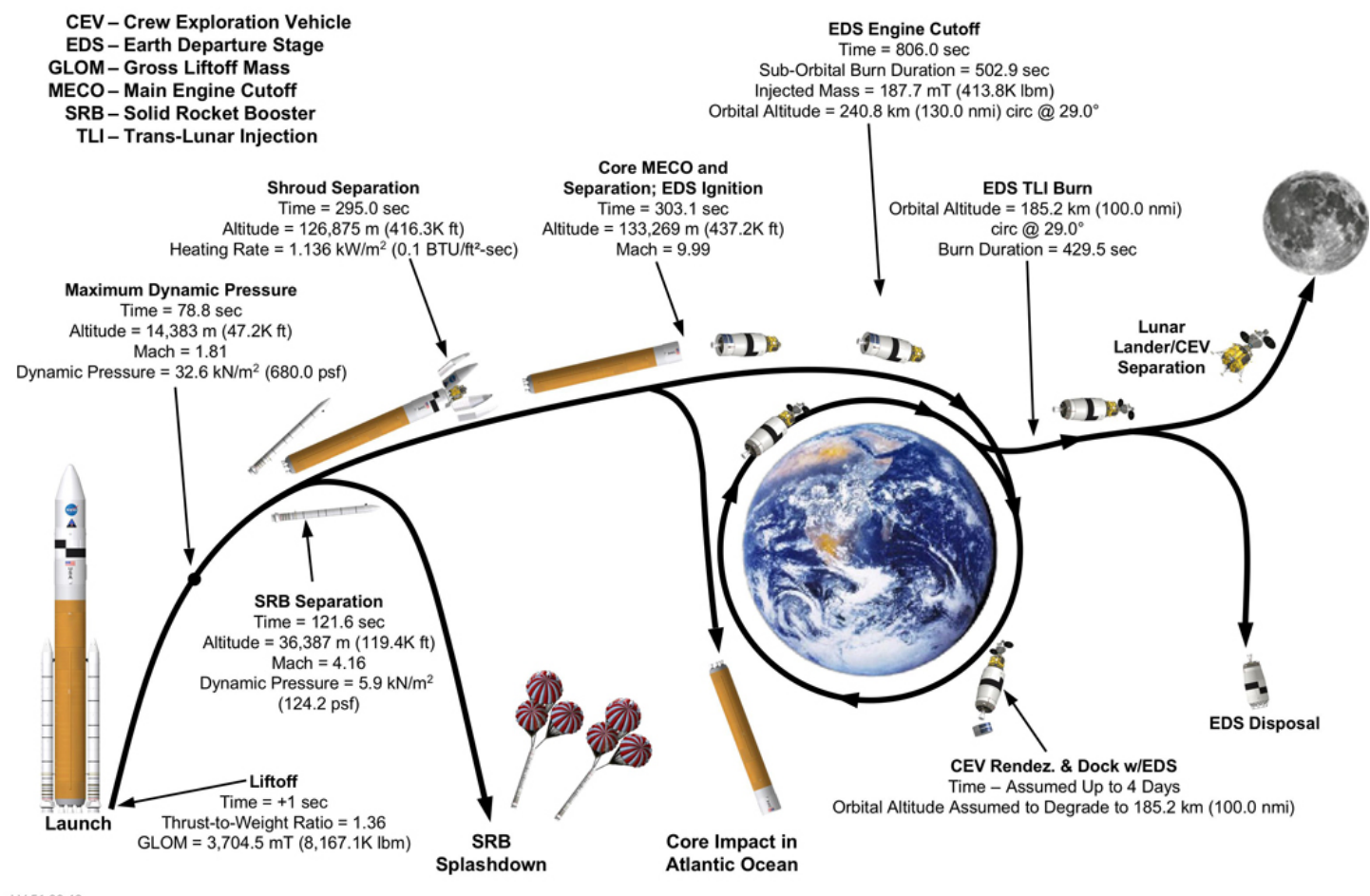

Figure 5. Ares V profile for the dual-launch design reference mission lunar sortie.

\section{Ares V Design Evolution}

Ares $\mathrm{V}$ is the largest vehicle in a planned fleet that will support NASA's aggressive goal of going beyond the Apollo missions to establish a permanent human presence on the moon, sending more crew to more locations on the moon's surface, and conducting more detailed exploration and science. That goal translates into higher Constellation mass and volume launch requirements. The latest point of departure (POD) configuration meets the current Constellation Architecture Requirements Document (CARD) TLI mass of 147,575 pounds (66.9 mT) to TLI in conjunction with Ares I with $6 \mathrm{mT}$ of margin. However for the crewed human lunar mission, the Ares $\mathrm{V}$ target is a TLI payload of $75.1 \mathrm{mT}$, including $45 \mathrm{mT}$ for the Altair lander and $20.2 \mathrm{mT}$ for Orion, plus program margin. As mentioned earlier, the Saturn V TLI payload capability was 99,000 pounds (44.9 mT) to TLI. The Ares V TLI payload capability, then, exceeds the Saturn $\mathrm{V}$ capability by more than 30 percent in single-launch mode or by more than 50 percent in its Ares I/Ares V dual launch mode.

The first configurations for the Ares I and Ares V were proposed during the Exploration Systems Architecture Study (ESAS), which began in 2005. The vehicles selected in the ESAS were based on the goal of using existing space shuttle propulsion elements and other heritage hardware. Since the ESAS process began in 2005, the Ares V team has analyzed more than 1,700 vehicle concepts, based on Constellation mission requirements and increasingly more refined evaluations of Orion, Altair, and Ares V design and performance. An overview of the Ares V development history is shown in Figure 6 below, including the Interim Design Analysis Cycle (IDAC) trades in 2007 and the Lunar Capabilities Concept Review (LCCR) trades in 2008.

The ESAS-recommended Ares I propulsion elements consisted of a modified 4-segment Space Shuttle Polybutadiene Acrylonitrile (PBAN) fueled booster for the First Stage and an RS-25 Space Shuttle Main Engine, modified to be low-cost, expendable, and start at altitude, for the Upper Stage. The ESAS-recommended Ares V vehicle, designated Concept 27.3, included two 5-segment boosters with Hydroxyl-Terminated PolyButadiene (HTPB) propellant, which has a higher specific impulse $\left(\mathrm{I}_{\mathrm{sp}}\right)$, density, and better mechanical properties than PBAN. Concept 27.3 also had a 27.5-foot-diameter Space Shuttle External Tank-derived core stage powered by five RS-25 
space shuttle main engines redesigned to be low-cost and expendable, and an EDS powered by two $\mathrm{LOX} / \mathrm{LH}_{2} \mathrm{~J}-2 \mathrm{~S}+$ engines. The J-2S+ was intended to be a simplified version of the $\mathrm{J}-2$ engine used for the Saturn upper stages. That Ares $\mathrm{V}$ variant had a gross liftoff weight (GLOW) of nearly 6.4 million pounds.

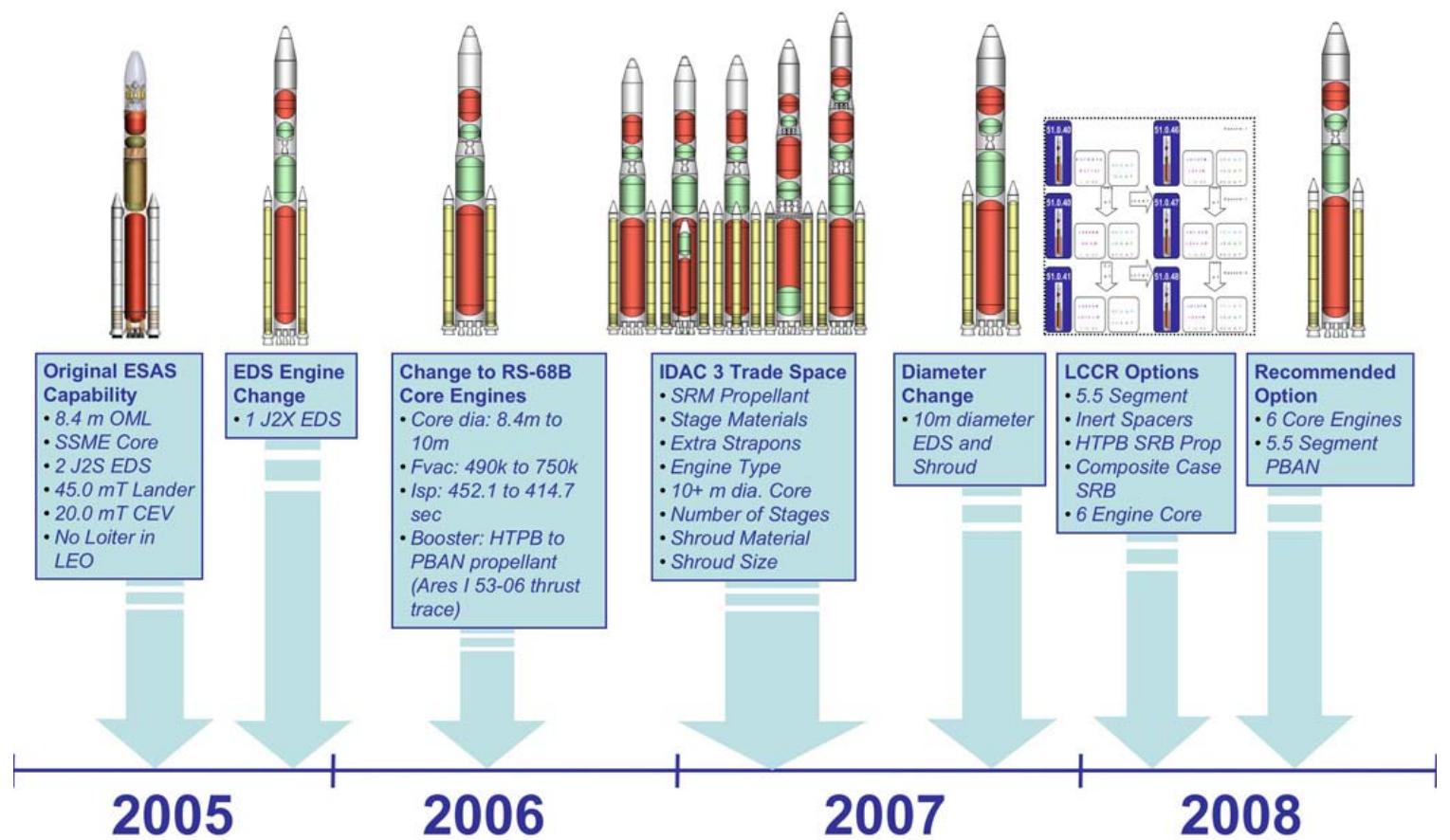

Figure 6. Major Ares V design milestones from ESAS to LCCR.

In the subsequent NASA studies to refine the ESAS recommendations, the architecture was simplified to reduce the number of new development programs. Ares I propulsion changed from the 4-segment booster to the 5-segment booster for the First Stage and from the RS-25 to the new J-2X engine for the Upper Stage (Figure 7). The J-2X is designed to retain the J-2 engine's simpler gas generator cycle, yet provide both higher thrust and higher efficiency than its Saturn-era predecessor to meet the greater Constellation requirements. The J-2X was then able to replace the two J-2S+ engines on the Ares V EDS, contributing to greater commonality between Ares launch vehicles.

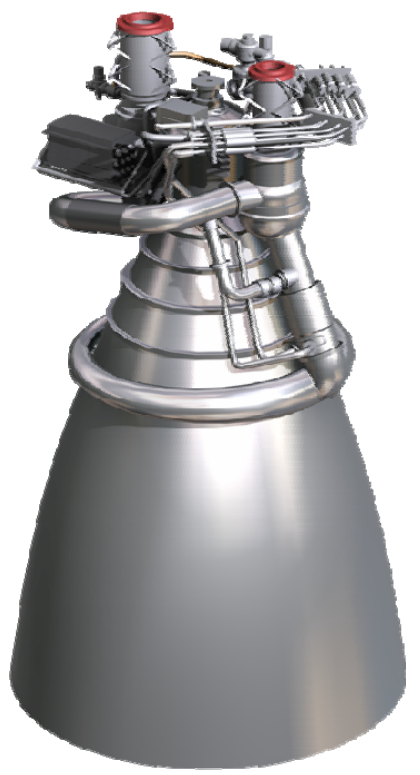

Figure 7. The J-2X Upper Stage Engine for the Ares I and Ares V. 
Looking to reduce design, development, test, and evaluation (DDT\&E) and out-year costs, NASA dropped the RS-25 from the core stage and employed instead an enhanced RS-68, referred to as the RS-68B. Because of the RS68B's lower efficiency, the core stage was enlarged from 27.5 feet $(8.4 \mathrm{~m})$ to 33 feet $(10 \mathrm{~m})$ in diameter to hold the extra required propellants and accommodate the larger nozzle and exhaust clearances needed for the 5-engine cluster. The lower initial and recurring costs of the RS-68B, as well as the cost, technical, schedule, and reliability risks involved with redesigning the RS-25 for altitude start, outweighed the cost of developing Saturn-class tooling and facilities needed to manufacture and process the larger 33-foot core stage. The booster design also reverted from HTPB to PBAN solid propellant for its better technical maturity. The resulting Ares V configuration, designated Concept 33.8.64, had a GLOW of 7.3 million pounds and was nearly 362 feet tall. It exceeded the payload performance of the RS-25 solution by approximately four metric tons to TLI and enhanced the commonality between the Ares vehicles, improving both development and operational efficiencies.

In subsequent configuration trades involving shroud diameter, direct lunar missions, using the Ares I Upper Stage on Ares V, gravity losses on TLI burns, and flight performance reserve (FPR) mass, Concept 33.8.64 evolved into Concept 45.0.2. Nearly 365 feet tall, the new concept served as a benchmark to determine the effect of enhancements, such as engine upgrades, solid rocket booster (SRB) variations, alternate materials, added stages, added boosters, added engines and stage diameter. That effort determined that replacing steel structures with composites could add 4 metric tons (mT) of payload. Additional core stage propellant, a sixth RS-68B engine, and a 5.5-segment booster in combination could add between 6 and $8 \mathrm{mT}$ of payload. HTPB-fueled SRBs with composite cases could add $5 \mathrm{mT}$. Another pair of SRBs could add $20 \mathrm{mT}$, and a Saturn S-II class second stage could add 4 to 8 $\mathrm{mT}$. The study also concluded that composite propellant tanks had a high technical risk. HTPB boosters and a third stage carried undesirably high DDT\&E costs. Additional SRBs incurred undesirably high launch pad modification costs, and vehicles more than 400 feet tall led to higher KSC facility costs.

The 45-series of vehicles served as the starting point for trades that became the new 51-series of Ares $\mathrm{V}$ concepts, which, in turn, served as the trade space for the Lunar Capability Concept Review (LCCR) in June 2008. Figure 8 illustrates the LCCR trade space for the 51-series configurations, including the 51.00.39 entry point and the recommended new point-of-departure (POD).

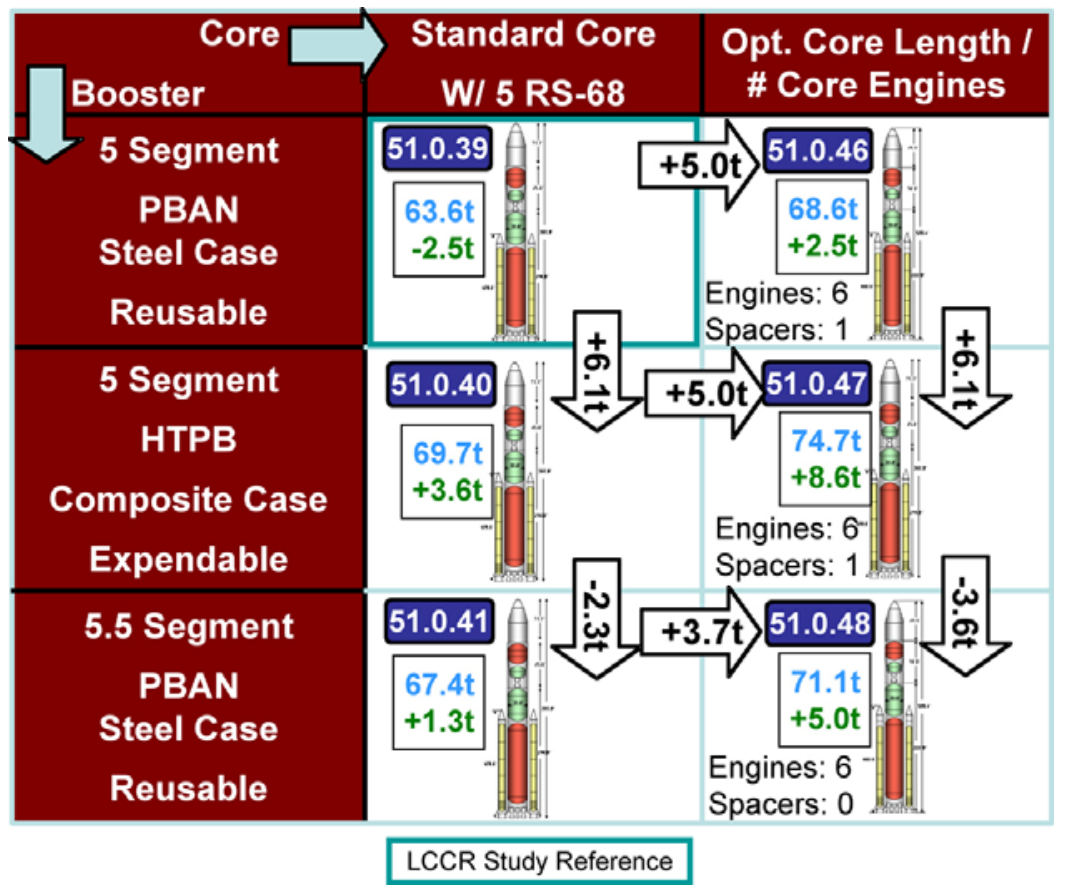

Figure 8. LCCR trade space for the 51-series of Ares V configurations.

The goal of LCCR was to develop a consistent, compatible definition of the lunar transportation system architecture, its performance envelope, and a risk assessment associated with delivering that transportation system. The LCCR 51-series trades included a larger core stage propellant load, PBAN versus HTPB propellant, 5-segment booster vs. 5-segment booster with an inert spacer to support a lengthened core stage vs. 5.5-segment booster, and the addition of a sixth RS-68B engine. Common design features included: composite structures for the shroud and 
core stage and EDS dry structures, metallic cryogenic tanks for the core stage and EDS, RS-68B $\mathrm{I}_{\mathrm{sp}}$ of 414.2 seconds and 797,000 pounds thrust, $\mathrm{J}-2 \mathrm{X} \mathrm{I}_{\mathrm{sp}}$ of 448 seconds and 294,000 pounds thrust, $10 \mathrm{~m}$ diameter $\mathrm{x} 9.7 \mathrm{~m}$ length for the shroud barrel, 4-day loiter period, insertion orbit of $130 \mathrm{nmi}$ and 29 degrees inclination, $100 \mathrm{nmi}$ TLI departure altitude, and TLI payload goal of $75.1 \mathrm{mT}$.

The Ares Projects' POD concept for the LCCR trades was Concept 51.00.39. It employs five RS-68B engines, two 5-segment PBAN steel case boosters, aluminum-lithium (Al-Li) core stage and EDS propellant tanks, and composite structures for payload shroud and core stage and EDS dry structures. The EDS and payload shroud diameters were increased from 27.5 feet (8.4 meters) to 33 feet (10 meters). The overall vehicle was 361 feet (110 m) tall, with a GLOM of 7.4 million pounds (3,375 mT).

The Constellation operations concept was also changed. The Ares V LEO loiter period was reduced from 14 days to 4 days. The LEO injection altitude was increased from $120 \mathrm{nmi}$ to $130 \mathrm{nmi}$. The orbital inclination was changed from 28.5 degrees to 29 degrees, improving rendezvous opportunities with minimal impact to performance or launch window.

The new 51.00.48 POD, as indicated earlier, is a vehicle that is roughly 20 feet longer, including 13.3 feet in length to the core stage hydrogen tank below the SRB forward cross beam, 4.9 feet to the LOX tank above the forward cross beam, and 2.5 feet in length to the EDS for longer burn duration. It also uses a sixth RS-68 core stage engine and adds a half segment to the previous 5-segment, steel case SRB design (Figure 9).

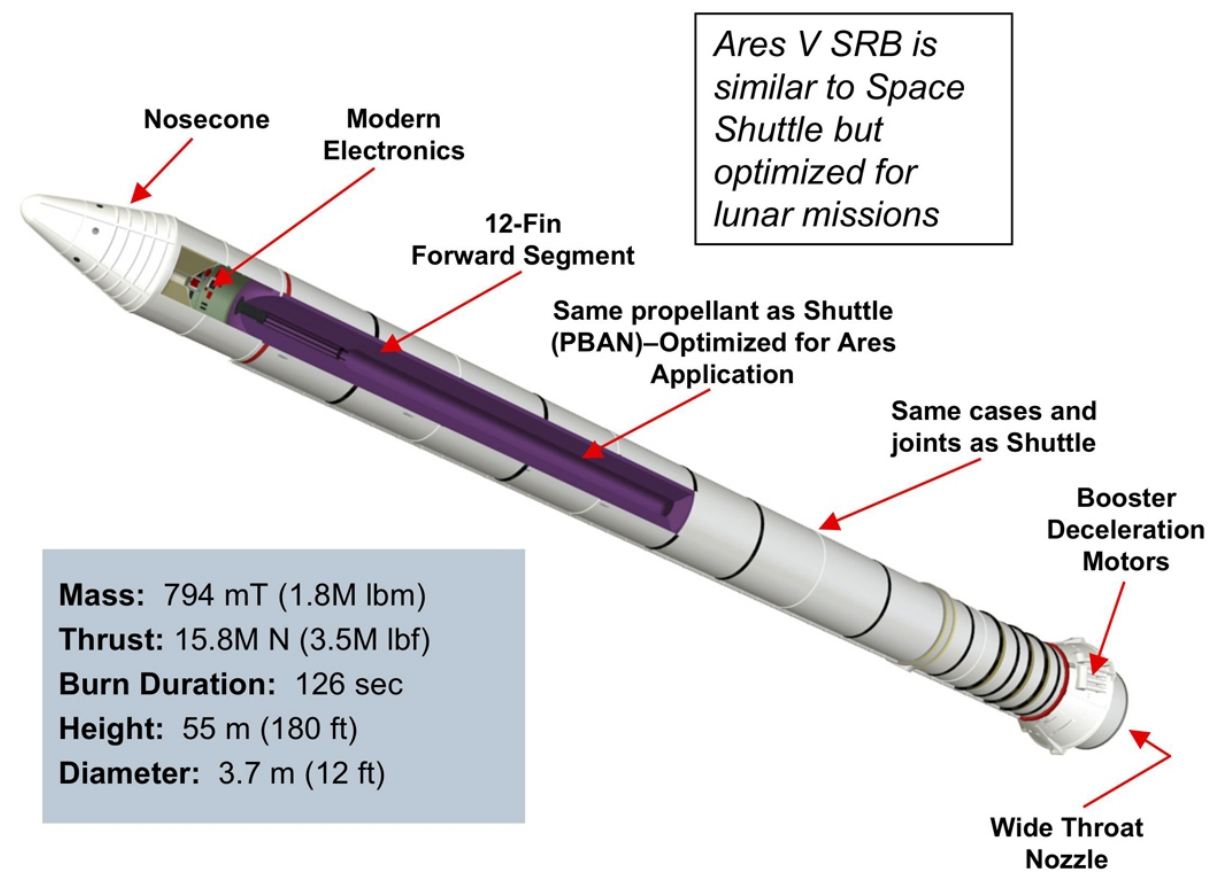

Figure 9. 5.5-segment SRB for Ares V.

Like the other trade space options, it employs composite dry structures and Al-Li propellant tanks for the core stage and EDS. NASA further accepted the Ares V recommendation at LCCR to maintain concept 51.00.47, with composite booster cases and more energetic HTPB propellant as an option. The final decision will be made at the Constellation Lunar Strategic Requirements Review scheduled for 2010. It would provide additional performance capability if needed for margin or requirements and allows for competitive acquisition for the booster. In the interim, maintaining that option requires continued exploration of key technologies, including composite cases and HTPB propellant characterization.

Studies of the 51.00.39 concept, meanwhile, serve as the basis for the current Ares V Concept Validation Study, begun in early 2008, which is aimed at closing the design with Ares I, Orion, and Altair systems, plus the desired program reserve margins. The Concept Validation Study provides a detailed analysis of the integrated vehicle and validates the conceptual design work done on the core stage, EDS, and payload shroud to date. The study will identify technical issues with the design and areas of performance risk. It also will provide the data for the Advanced Concepts team to upgrade its performance and sizing tools if needed. The final product will be a data book and 
series of analyses that will be the technical foundation for a new Ares V Reference Concept and areas for further study.

\section{Detailed Analysis and other Risk Mitigation}

While concept analyses were under way in 2007 and 2008, detailed studies were also being pursued to optimize designs and examine technical issues associated with the Ares V elements such as the EDS, payload shroud, boosters, and RS-68 engine. The findings of those studies were provided to the Concept Validation Study begun by MSFC in 2008 to prepare for an ATP decision.

Glenn Research Center conducted a series of design trades and analyses on the EDS. Major areas of study were aimed at providing more detail to the EDS design; these included structural changes to increase payload, on-orbit power requirements, insulation to prevent propellant boil-off during loiter, and micrometeoroid/orbital debris (MMOD) protection required for on-orbit loiter. Studies also considered interactions with, and support to, the Altair lander, including providing power from solar arrays, batteries, or fuel cells. The study also considered composite materials, lighter structures, and eliminating structure by using nested, conformal, and common bulkhead tanks for weight reduction potential. The team also considered dual use of structures as MMOD protection, reducing consumables, transferring weight from the EDS to the core stage, and jettisoning loiter hardware such as MMOD protection, power, insulation, and propellant tanks before the TLI burn.

The EDS study recommended a baseline cargo configuration free from additional loiter protection, but adaptable to several loiter kits for crewed EDS missions requiring rendezvous with Orion before TLI, shown in Figure 10. The loiter kits could be jettisoned as appropriate before the TLI burn. Loiter kits would include MMOD protection, boiloff insulation, an MMOD loiter skirt containing fuel cells surrounding the J-2X engine, reaction control system (RCS) propellant, and different configurations of batteries and fuel cells for the loiter skirt and forward skirt. The 5hour cargo loiter period required significantly less power and other resources power than the 4-day crewed loiter period. While the crewed loiter kit provided 111,000 pounds of payload - 8,000 pounds short of desired performance - the cargo EDS provided 138,000 pounds of payload, a surplus of more than 5,000 pounds over the requirement. A natural area for further study is the possibility of offloading some of the crewed payload to a cargo flight.

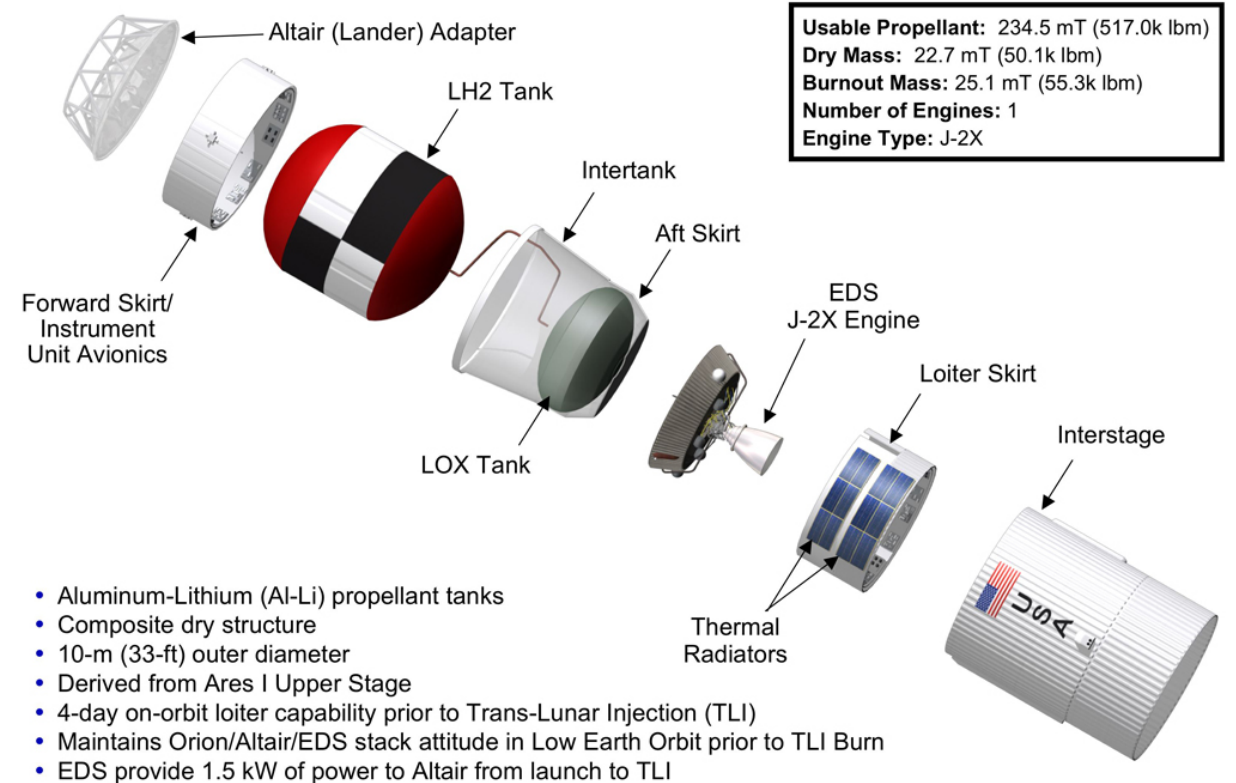

Figure 10: Expanded view of 10-meter EDS structure including Interstage.

The study also examined MMOD protection, propulsion and power subsystems, on-orbit loiter issues, power options, discussed in this section. The power subsystem evaluation concluded that solar arrays are best for power needs longer than 7 days. For less than 7-day periods, dedicated fuel cells are better than solar arrays due to fuel 
cells having comparable or less mass, no deployment issues, and less sensitivity to attitude as compared to solar arrays, which require fuel to maintain solar orientation for maximum power generation. Battery options are only feasible for time periods less than 10 hours. Boil-off fuel cell types seem more mass competitive than options using dedicated fuel cells or solar arrays. However, their complexities make them less favorable. Another option meriting further investigation would be using the Altair fuel cells in combination with reactants stored in the EDS tanks to provide EDS power. Space Shuttle fuel cell tanks might have been used, but that was unlikely due to the desire for commonality in fuel cell systems. Altair and lunar base systems are based on Proton Exchange Membrane (PEM) fuel cells, which are lighter and produce less heat than the Space Shuttle fuel cells. The EDS cargo option had more batteries than the crew loiter option due to the difference in mission duration and power levels.

Propulsion subsystems were evaluated based on preliminary configurations for both baseline and drop tank main propulsion system (MPS) configurations and the RCS configuration. Studies generally concluded that redundancy levels needed to be examined in greater detail for trade configurations. Better information on large components was also needed and should be incorporated into the modeling. The propulsion evaluation noted that the EDS is unique for its in-space restart, long-term operation of pneumatic control, long-term storage of cryogenic propellants, use of an $\mathrm{O}_{2} / \mathrm{H}_{2}$ burner, and long-term operation of thrust vector control (TVC) in space. An evaluation of cryogenic systems concluded that separate tanks were preferable because common bulkhead heat loads were too high for missions longer than a few days. Multilayer insulation (MLI) was the only viable insulation for MMOD protection for missions over a few days. The evaluation further recommended using pulse flow instead of a recirculation pump to eliminate heavy hardware and reduce heat loads, using RCS settling instead of ullage motors, and engaging in intermittent propellant settling instead of continuous settling for mission durations of more than a few hours.

Results of a LEO loiter orbital decay and attitude study were shaped by limits on Orion's rendezvous altitude, rendezvous window durations, power shortfalls, and orientation needs. As a result, the study concluded that launching to a higher altitude and accepting drag even for worst-case EDS orientations was preferable to reboosting the EDS during loiter. An analysis of various stack loiter attitudes (Figure 11) concluded that the gravity gradient orientation was the preferred option because it required the least amount of propellant. With an insertion altitude of 130 nautical miles to avoid the need for reboost, orbital decay is slow enough to meet rendezvous and TLI goals. This preference for 130 nautical mile LEO insertion altitude presented a challenge because the Orion design is based on a 160 nautical mile insertion altitude. Efforts are being made to resolve the discrepancy in the insertion altitude.

- Gravity Gradient

- Orion "Up"

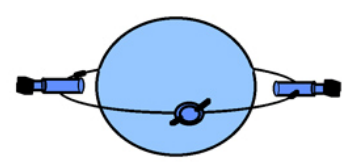

- Sun-Pointing

- Orion main engine sun-facing

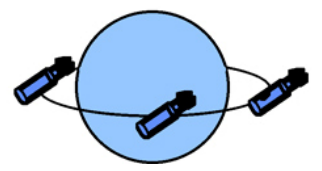

- XVV

- X (stack long axis) along Velocity Vector

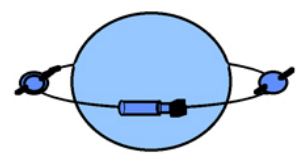

- XPOP Inertial

- X (stack long axis) Pointing Out-of Plane

- Orion ME (mainly) sun-facing

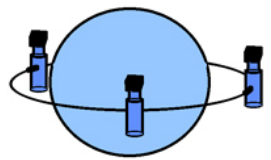

Figure 11: Stack loiter attitudes assessed.

A shroud study team began work in 2007 to develop an initial concept and weight estimate for future trades and a basis for shroud development costs. The team's point of departure (POD) shroud was a quad-pedal bi-conic shape, with composite sandwich construction, and a painted cork thermal protection system (TPS) bonded to an outer face sheet. The design also specified the payload environmental control system, avionics, and separation system. Analysis included geometry definition, aero-pressures at critical loads, aeroacoustics at transonic Mach numbers, aero-heating along the flight profile, TPS sizing, structures sizing, and subsystem mass estimation for acoustic blankets, separation systems. Among the key findings of the first phase of studies released in October 2007: the small base flair on the POD caused a significant pressure spike at max Q; acoustic levels can be reduced using a 
smooth ogive nose shape; spray-on foam insulation (SOFI) could substantially reduce the use of cork-based TPS mass; and a global buckling check indicated a positive but low margin of safety. A subsequent analysis cycle took a closer look at drag, acoustics, and other aspects of the bi-conic POD to achieve the best payload performance. The study also considered decreasing lander mass by using the shroud to support the lander during launch to orbit and possibly TLI mission phases. Options referred for wind tunnel testing are shown in Figure 12.

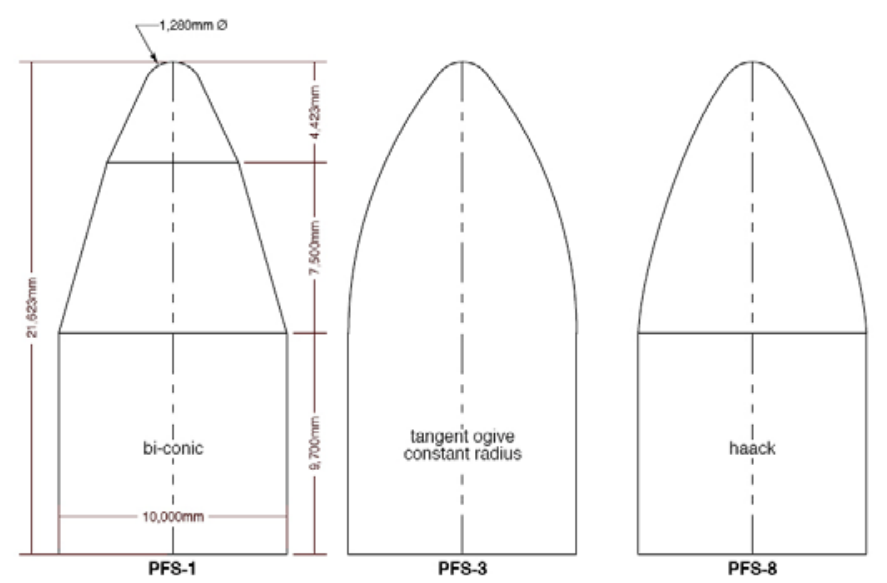

Figure 9: Payload shroud shapes delivered to MSFC to support wind tunnel tests.

\section{Other Progress and Forward Plans}

In 2006, work was begun to understand the changes required in the RS-68 engine to meet NASA requirements using seed money from Congress. A test rig is being built to test an intermediate seal re-design to reduce helium usage in the RS-68. Helium spin start testing on the engine is planned for later this year at Stennis Space Center. Forgings for the required modifications purchased with 2007 funding are due to be delivered to MSFC in 2008. This potential intermediate seal redesign could reduce consumption of increasingly expensive helium. Pratt \& Whitney Rocketdyne proposes designing and building a development gas generator and helium spin start duct based on the seal test results and also bringing the design of a segmented carbon ring seal to critical design review level, allowing for testing at MSFC. These efforts can be completed before authority to proceed (ATP) in 2011, will save a year in schedule, and will allow the Main Propulsion Test Article (MPTA) engines to be delivered on time.

Planning is under way for a core stage engineering study. Aerothermal and structural analysis is continuing on six-engine configurations. Of particular interest is the geometry, which will include an analysis of the best arrangement for the RS-68 cluster relative to each other and the adjacent SRBs.

Studies continue on Ares V booster options with investigations of HTPB propellant, structure, and thrust issues related to increased booster length as well as nozzle options of different lengths, throat diameters, expansion ratios, and performance. Additional work is under way or planned to understand long-term cryogenic fluid management; manufacturing, processing, logistics, damage tolerance, detection and joining of large composite structures; EDS LEO loiter issues, attitude control, EDS state determination, injection altitude, power supply to Altair, HTPB characterization, risk, cost estimating and reliability. Manufacturing space at Michoud Assembly Facility is being assessed to include the impact of a 40-foot autoclave and a new shroud manufacturing area. Issues associated with integrated testing are under study, including the location for a large-scale cryo-structural test facility, conversion of the A-2 test stand at Stennis Space Center for EDS testing, EDS orbital simulation testing, development of an integrated test schedule, and an EDS test and verification plan.

The new Ares V Concept Validation Study mentioned above will be receiving inputs from all hardware, testing, and operations studies to develop a detailed concept that will be provided to industry for one or more study contracts. A summary schedule of Ares V development plans leading to the first series of launches is shown in Figure 13. These and other ongoing studies, analyses, and tests will ensure that Ares V can meet its scheduled test flight program late in the next decade and support human flights to the moon in the 2020 timeframe. 


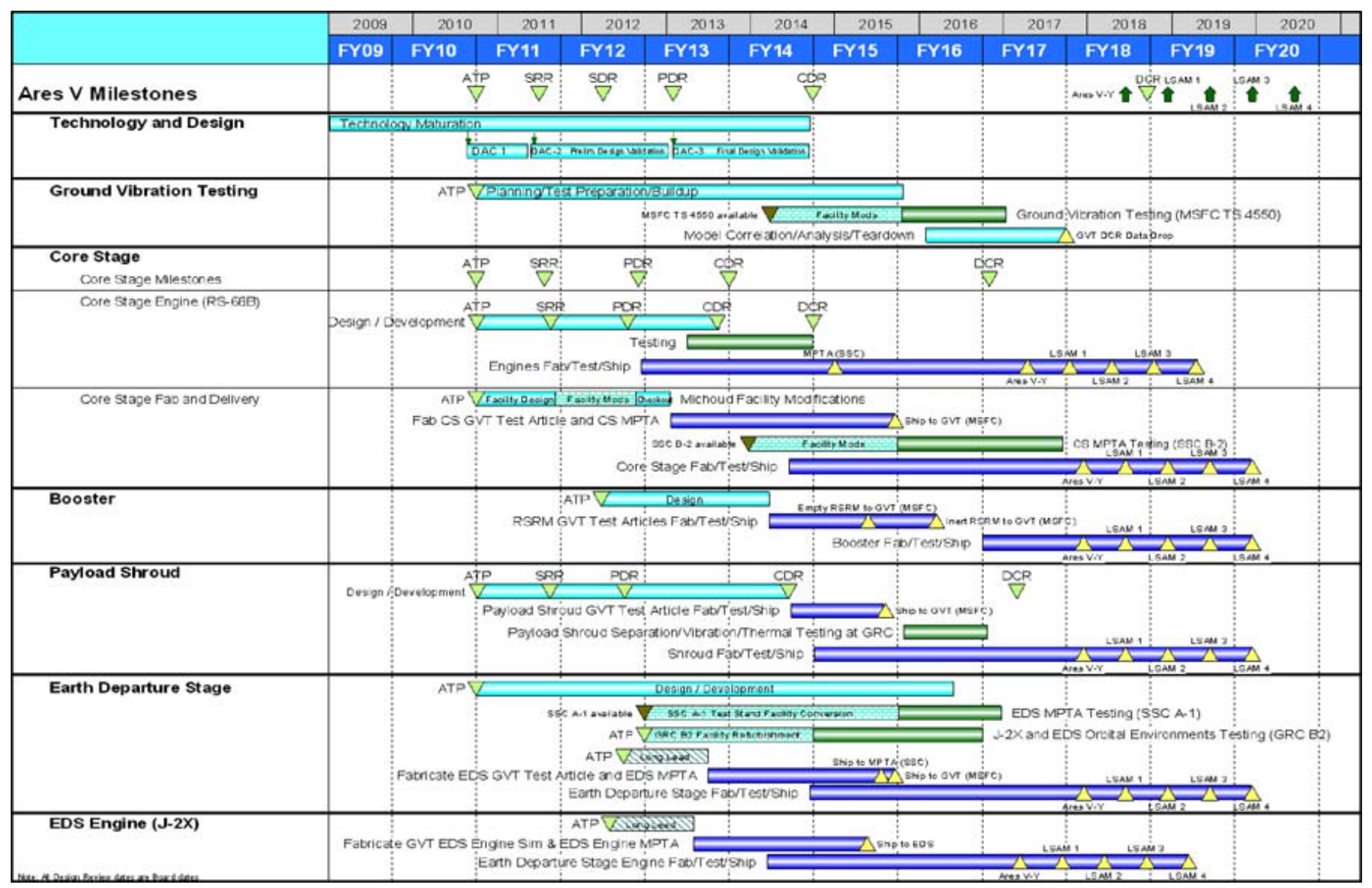

Figure 13. Ares V summary schedule

The Ares Projects are also reaching out to the academic and government communities for science and military missions that may benefit from the Ares V capabilities: specifically space-based astronomy missions to the outer solar system and beyond.

\section{Conclusion}

NASA's Ares Projects are fully engaged in designing the Ares I and Ares V launch vehicle systems for safety, simplicity, robust operability, and streamlined supportability to reduce operations costs, allowing NASA to focus more resources on exploration and discovery. Ares V's unmatched mass and volume capability will make it a valued national asset that can support a number of potential users beyond the Constellation Program. With authority to proceed planned for 2011 and critical design review planned for 2014, Ares V will be ready for a scheduled first launch in 2018 and many history-making expeditions to follow. 